\title{
THE FIFTH-ORDER KORTEWEG-DE VRIES EQUATION
}

\author{
G. ADOMIAN \\ General Analytics Corporation \\ 155 Clyde Rd. \\ Athens, GA 30605, USA
}

(Received December 13, 1994)

ABSTRACT. Decomposition is applied to the 5th-order KdV equation.

KEY WORDS AND PHRASES. Decomposition method, Adomian Polynomials.

\section{AMS SUBJECT CLASSIFICATION CODES.}

The 5th-order $\mathrm{KdV}$ equation [1] is given by:

$$
u_{t}+6 u u_{x}+u_{x x x}+u_{x x x x x}=0 .
$$

Writing $L_{t}=\partial / \partial t$ and $L_{t}^{-1}=\int_{0}^{t}(\cdot) d t$, we have

$$
\begin{aligned}
L_{t} u & =-6 u u_{x}-u_{x x x}-u_{x x x x x} \\
L_{t}^{-1} L_{t} u & =-6 L_{t}^{-1} u u_{x}-L_{t}^{-1} u_{x x x}-L_{t}^{-1} u_{x x x x x} \\
u & =u(0)-6 L_{t}^{-1} A_{n}\left\{u u_{x}\right\}-L_{t}^{-1}\left(\partial^{3} / \partial x^{3}\right) u-L_{t}^{-1}\left(\partial^{5} / \partial x^{5}\right) u
\end{aligned}
$$

where $A_{n}\left\{u u_{x}\right\}$ represents the Adomian Polynomials [2] for $u u_{x}$. Letting $u=\sum_{n=0}^{\infty} u_{n}$, decomposition yields

$$
\begin{aligned}
u_{0} & =u(0) \\
u_{1} & =-6 L_{t}^{-1} A_{0}-L_{t}^{-1}\left(\partial^{3} / \partial x^{3}\right) u_{0}-L_{t}^{-1}\left(\partial^{5} / \partial x^{5}\right) u_{0} \\
u_{2} & =-6 L_{t}^{-1} A_{1}-L_{t}^{-1}\left(\partial^{3} / \partial x^{3}\right) u_{1}-L_{t}^{-1}\left(\partial^{5} / \partial x^{5}\right) u_{1} \\
\vdots & \\
u_{n+1} & =-6 L_{t}^{-1} A_{n}-L_{t}^{-1}\left(\partial^{3} / \partial x^{3}\right) u_{n}-L_{t}^{-1}\left(\partial^{5} / \partial x^{5}\right) u_{n}
\end{aligned}
$$

Using primes to indicate the differentiation with respect to $x$ [2]

$$
\begin{aligned}
A_{0} & =u_{0} u_{0}^{\prime} \\
A_{1} & =u_{0} u_{1}^{\prime}+u_{1} u_{0}^{\prime} \\
A_{2} & =u_{2} u_{0}^{\prime}+u_{1} u_{1}^{\prime}+u_{0} u_{2}^{\prime} \\
\vdots & \\
A_{n} & =u_{n} u_{0}^{\prime}+u_{n-1} u_{1}^{\prime}+\ldots+u_{1} u_{n-1}^{\prime}+u_{0} u_{n}^{\prime}
\end{aligned}
$$

Now all components of $u$ are determinable and we can write the $n$-term approximant

$$
\phi_{n}=\sum_{m=0}^{n-1} u_{m}
$$

which approaches $u$ as $m \rightarrow \infty$. It has been shown that high accuracy can be achieved for small values of $n$.

\section{REFERENCES}

[1] BOYD, J.P., Weakly nonlocal solutions for capillary-gravity waves: 5th-degree KdV equation, Physica D, 48 (1991), 129-146.

[2] ADOMIAN, G., Solving Frontier Problems of Physics: The Decomposition Method, Kluwer Acad. Publ., 1994.

[3] ABBAOUI, K. and CHERRUAULT, Y., Convergence of Adomian's method applied to differential equations, Comp. Math. Applic., 28, no. 5 (1994), 103-109. 


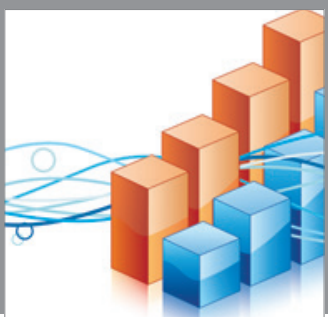

Advances in

Operations Research

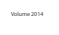

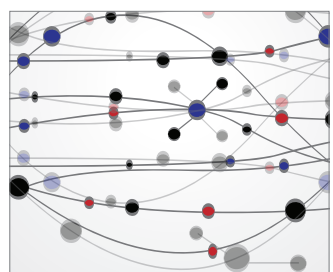

\section{The Scientific} World Journal
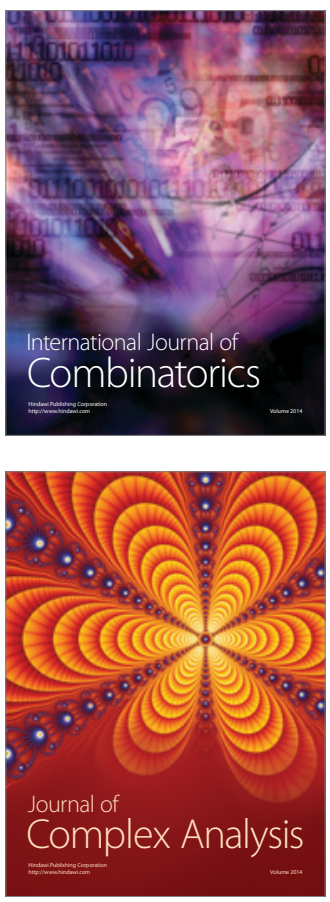

International Journal of

Mathematics and

Mathematical

Sciences
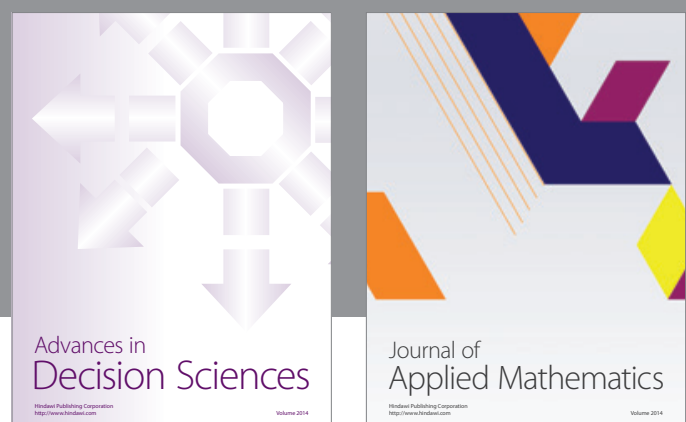

Journal of

Applied Mathematics
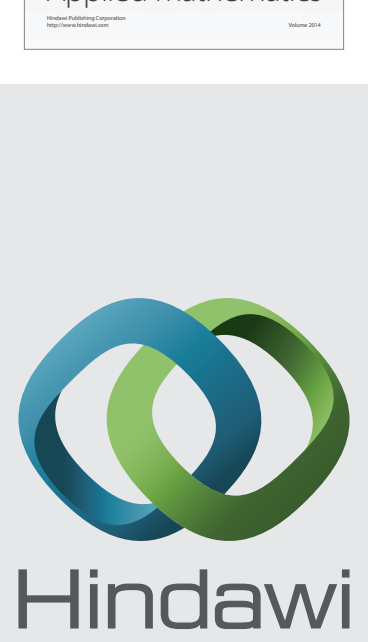

Submit your manuscripts at http://www.hindawi.com
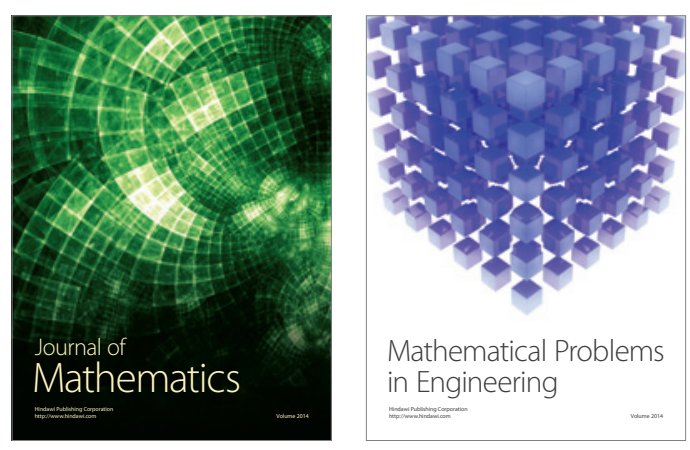

Mathematical Problems in Engineering
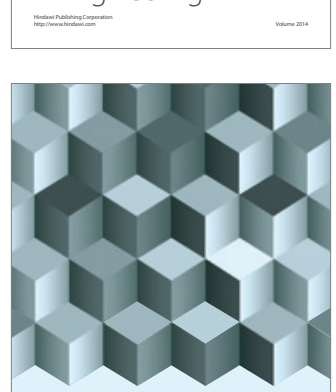

Journal of

Function Spaces
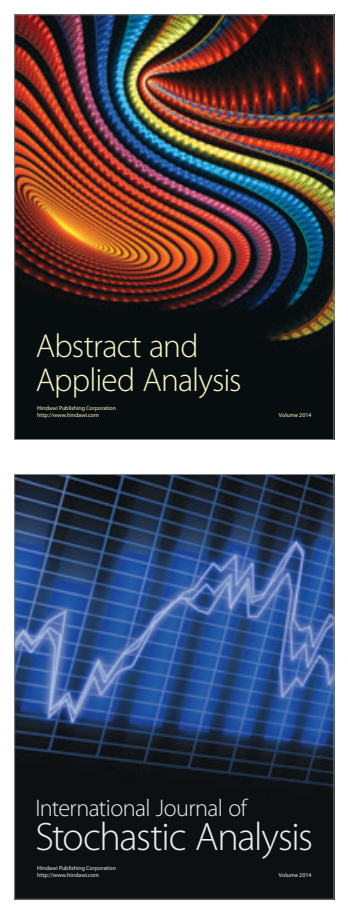

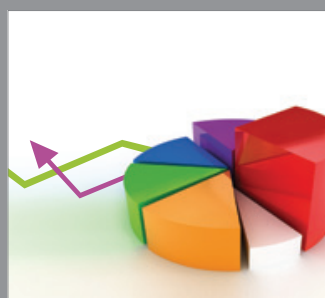

ournal of

Probability and Statistics

Promensencen
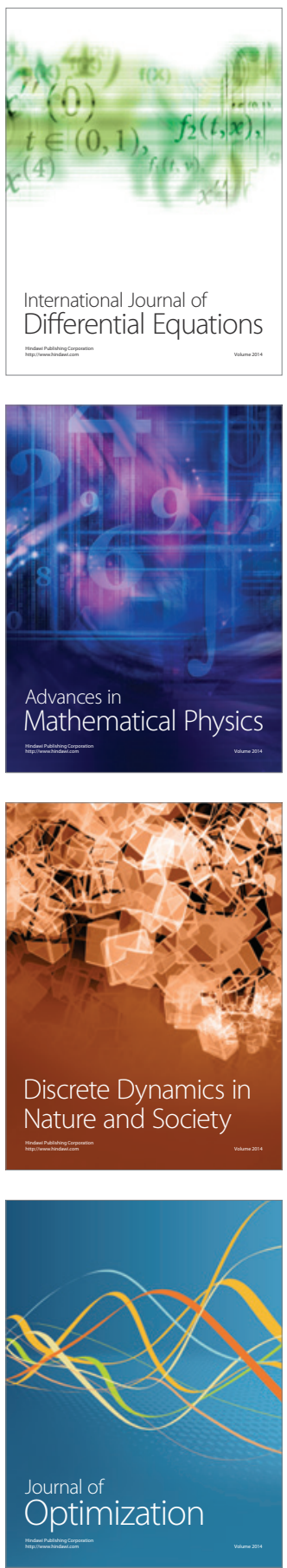